\title{
Ethylene glycol as bore fluid for hollow fiber membrane preparation
}

\author{
Ngoc Lieu Le and Suzana P. Nunes ${ }^{1 *}$ \\ ${ }^{1}$ King Abdullah University of Science and Technology (KAUST), \\ Biological and Environmental Science and Engineering Division (BESE), \\ Thuwal, 23955-6900, Saudi Arabia \\ *Corresponding authors: \\ Prof. Suzana Nunes \\ Email address: suzana.nunes@kaust.edu.sa
}

Tel.: +966 544700052 


\begin{abstract}
We proposed the use of ethylene glycol and its mixture with water as bore fluid for the preparation of poly(ether imide) (PEI) hollow fiber membranes and compared their performance and morphology with membranes obtained with conventional coagulants (water and its mixture with the solvent N-methylpyrrolidone (NMP)). Thermodynamics and kinetics of the systems were investigated. Water and 1:1 water:EG mixtures lead to fast precipitation rates. Slow precipitation is observed for both pure EG and 9:1 NMP:water mixture, but the reasons for that are different. While low osmotic driving force leads to slow NMP and water transport when NMP:water is used, the high EG viscosity is the reason for the slow phase separation when EG is the bore fluid. The NMP:water mixture produces fibers with mixed sponge-like and finger-like structure with large pores in the inner and outer layers; and hence leading to a high water permeance and a high MWCO suitable for separation of large-sized proteins. As compared to NMP:water, using EG as bore fluid provides fibers with a finger-like bilayered structure and sponge-like layers near the surfaces, and hence contributing to the higher water permeance. It also induces small pores for better protein rejection.

Keywords: hollow fiber, bore fluid, ethylene glycol, precipitation rate, kinetics.
\end{abstract}




\section{Introduction}

Along with membrane chemistry, membrane pore characteristics such as surface pore size, porosity and pore size distribution are crucial factors in ultrafiltration process because they contribute to determine water flux, solute rejection and even resistance to fouling [1]. In the phase inversion process, a versatile technique for fabrication of asymmetric ultrafiltration membranes, membrane pore structures can be tailored by changes in polymer dope composition, solvent evaporation temperature and duration, and the chemistry and temperature of the coagulation bath. The addition of pore-forming agents is an important strategy in membrane preparation to enhance permeation properties. These additives can be inorganic (e.g. water [2, 3], $\mathrm{LiCl}$ [3-6], $\mathrm{ZnCl}_{2}$ [7] or phosphoric acid [8]), small organic molecules (alcohols [3, 9], acetone [10], ethylene glycol [11] or glycerol [3, 8]) or organic macromolecules (e.g. poly(vinyl pyrrolidone) (PVP) [12-15] or poly(ethylene glycol) (PEG) [16-19]). Their action mechanism combines thermodynamic and kinetic aspects, such as coagulation capability, viscosity, phase separation mechanism and rate, diffusion coefficient, etc. For example, LiCl, glycerol and phosphoric acid are known to increase the viscosity of polyvinylidene fluoride (PVDF) dope solution, because of their stronger interactions with the solvent or polymer $[4,8]$, and the addition of PVP in the PVDF dope solution is reported to increase the precipitation rate in water due to its hydrophilic nature [12].

It is accepted that the fabrication of hollow fiber membranes involves additional factors to those involved in the flat-sheet membrane formation because of the large number of spinning parameters (polymer dope chemistry and flow rate, bore fluid composition and flow rate, spinneret design, air gap, take-up speed, etc.). Similar to the formation of flat-sheet membranes, many efforts have been made to investigate the introduction of additives in dope solutions to 
improve membrane pore characteristics. On the other hand, it has also been reported that the presence of additives in the bore fluid (i.e. internal coagulant) has significant effects on membrane pore structure. Most studies have used volatile solvents (e.g. ethanol [20]) or nonsolvent (water) [21] as such additives to control the pore formation in the lumen of the hollow fiber and adjust the internal skin. This method mostly changes the pore size of the internal surface and overall cross-sectional morphology, while the external skin (selective layer) remains unchanged when the strong non-solvent (water) is used as the external coagulant. In this study, we demonstrate that ethylene glycol added to the bore fluid can be used to tailor also the pore size of the external selective layer. Its similar compounds (e.g. diethylene glycol, glycerol and polyethylene glycol) have been known as pore-forming agents when added to polymer dope solutions, due to their high viscosity and hydrophilicity [3, 5, 22, 23]. However, to the best of our knowledge, there are no studies on the effects on ethylene glycol as a bore fluid component on membrane pore structure.

Aromatic poly(ether imide) (PEI) (Figure 1) was used for the fabrication of ultrafiltration hollow fiber membranes. PEI is a high performance membrane material for various applications. Its aromatic imide units offer high separation performance, while its flexible ether linkages facilitate good processability $[23,24]$. We believe this approach will be very useful for the optimization of spinning process for high-perfomance hollow fiber membrane preparation.

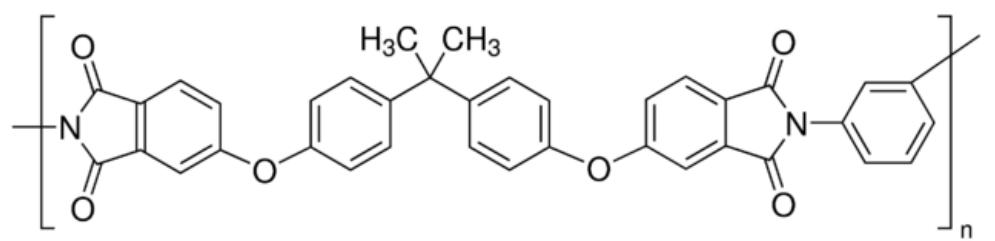

Figure 1. Chemical structure of PEI. 


\section{Experimental}

\subsection{Materials}

Polyetherimide (PEI) Ultem ${ }^{\circledR} 1000$, provided by Sabic (Saudi Arabia), diethylene glycol (DEG, 99\%, Alfa-Aesar), ethylene glycol (EG, 99.8\%, Sigma-Aldrich) and N-methyl-2-pyrrolidinone (NMP, $\geq 99.5 \%$, Merck) were used to prepare the dope solution and bore fluids for the fabrication of hollow fiber membranes. Poly(ethylene glycol) (PEG) and poly(ethylene oxide) (PEO) with different molecular weights from Sigma-Aldrich were used for pore size analyses. Myoglobin from equine skeletal muscle (95-100\%), bovine serum albumin (BSA, $\geq 96 \%$ ) and $\gamma$ globulin from bovine blood $(\geq 99 \%)$ for protein rejection tests were also obtained from SigmaAldrich. The information on their molecular weights and isoelectric points (pIs) are listed in Table 1 (from Sigma-Aldrich).

Table 1. Protein molecular weights and isoelectric points.

\begin{tabular}{lll}
\hline Protein & $\begin{array}{l}\text { Molecular } \\
\text { weight } \\
\left(\mathbf{k g ~ m o l}^{-1}\right)\end{array}$ & Isoelectric point \\
\hline Myoglobin & $\sim 17$ & $\sim 7.3$ \\
BSA & $\sim 66$ & $\sim 4.8$ \\
$\gamma$-Globulin & $155-160$ & $\sim 6.9$ \\
\hline
\end{tabular}

\subsection{Phase diagram}

The phase diagram of the PEI/NMP/DEG/EG/water system was estimated by cloud point tests. A series of PEI solutions with different polymer concentrations was prepared in DEG/NMP (13/70). Their cloud points were determined by adding different non-solvents (NMP:water (9:1), water, water:EG (1:1) and EG) at $60{ }^{\circ} \mathrm{C}$ (temperature at which PEI can be completely dissolved 
in NMP) until turbidity was observed. The amounts of PEI, DEG/NMP, and non-solvent for each cloud point were plotted in a ternary diagram.

\subsection{Phase inversion kinetics}

The phase inversion kinetics was studied by light transmittance experiments in different nonsolvents. The polymer solution was cast on a glass plate, forming a solution layer of $1 \mathrm{~mm}$ and then the glass plate was immediately immersed in a cuvette, containing non-solvent. The changes in light transmittance were monitored at $600 \mathrm{~nm}$ (water, NMP and EG have no absorbance peak at this wavelength) using a Cary 5000 UV-Vis-NIR, Agilent. The transmittance curves were plotted as a function of time.

\subsection{Hollow fiber spinning}

PEI hollow fiber membranes were fabricated by non-solvent-induced phase-separation process, using a dry-jet wet spinning line, as described in Figure 2. The detailed procedure can be found elsewhere [25] and spinning conditions are listed in Table 2. All spinning parameters were kept unchanged while different bore fluid compositions were used. The membrane modules were prepared with 2-3 fibers per module and their effective length was around $13.4 \mathrm{~cm}$. 
Table 2. Spinning conditions for PEI hollow fiber membranes.

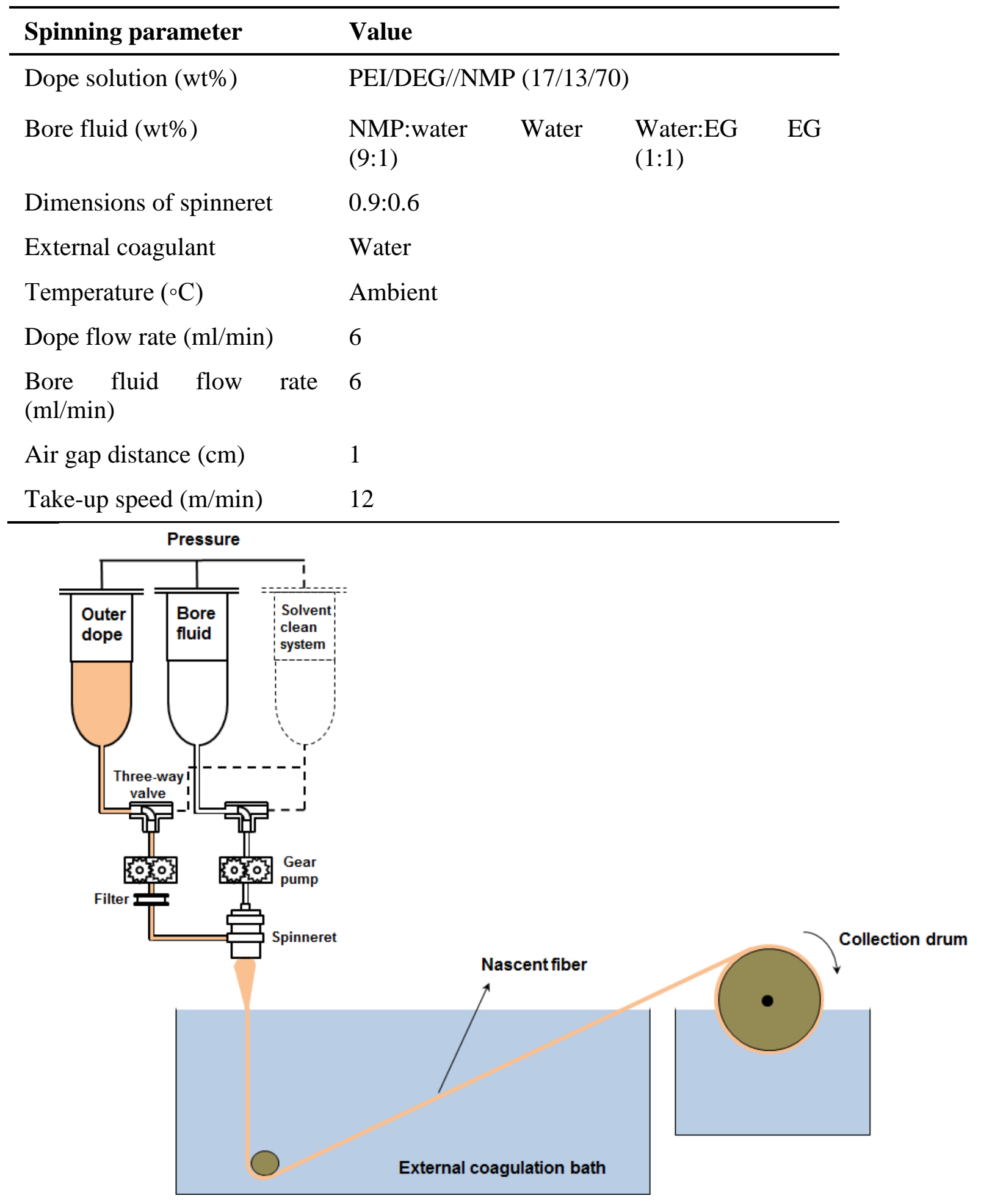

Figure 2. Schematic diagram of PEI hollow fiber membrane spinning system. 


\subsection{Membrane characterizations}

The cross-sectional and surface morphologies of PEI hollow fiber membranes were observed on a field emission scanning electron microscope (FESEM, Quanta 200 or Nova Nano). Before imaging, the membranes were fractured in liquid nitrogen and then coated with iridium, using a coater.

The water contact angle on the hollow fiber membrane surfaces, which characterizes their hydrophilicity, was measured by a Sigma 701 Tensiometer from KSV Instruments Limited. The hollow fibers were sealed at one end and then immersed into distilled water. Their advancing contact angles were calculated with the help of a computer software. Five readings were recorded and an average was obtained.

The porosity of hollow fiber membranes was determined by weight and volume measurements. Wet fibers were taken out from the water bath and cut into $5 \mathrm{~cm}$ in length (l) and then freeze dried overnight before weighed (m) with 5 samples for each measurement. The overall porosity $\varepsilon$ (\%) was calculated using the following equation:

$$
\varepsilon=\frac{\frac{1}{4} \pi l \rho\left(O D^{2}-I D^{2}\right)-m}{\frac{1}{4} \pi l \rho\left(O D^{2}-I D^{2}\right)} \times 100
$$

where OD and ID are the outer and inner diameters of the fiber, respectively. $\rho$ is the polymer density $\left(1.28 \mathrm{~g} / \mathrm{cm}^{3}\right)$.

The pore structural characteristics of PEI hollow fiber membranes, including pure water permeance, molecular weight cut-off (MWCO), pore size, and pore size distribution were analyzed, by using nanofiltration experiments in a lab-scale circulating filtration unit, as previously described [23]. Since the selective layer locates on the outer surface of the fibers, the 
feed solutions were circulated into their shell side, while the permeate solution were collected from their lumen side. The pure water permeance PWP $\left(\mathrm{L} \mathrm{m}^{-2} \mathrm{bar}^{-1} \mathrm{~h}^{-1}\right)$ was measured by circulating water into the module at a constant flow rate of $0.1 \mathrm{Lmin}^{-1}$ under a pressure of $1 \mathrm{bar}$ and then calculated using the equation:

$$
P W P=\frac{Q}{\Delta P \times A_{m}}
$$

where $\mathrm{Q}$ is the water permeation volumetric flow rate $(\mathrm{L} / \mathrm{h}), \mathrm{A}_{\mathrm{m}}$ is the effective area $\left(\mathrm{m}^{2}\right)$, and $\Delta \mathrm{P}$ is the transmembrane pressure (bar).

The pore size, pore size distribution, and MWCO of PEI hollow fiber membranes were evaluated via solute rejection experiments with 200 ppm neutral organic solutes (PEG and PEO with different molecular weights) at 1 bar. The system was stabilized for $1 \mathrm{~h}$ before both feed and permeate were collected 3 times for the consecutive time intervals of $0.5 \mathrm{~h}$. The variation of rejection was less than $2 \%$. Concentrations of feed and permeate were measured by gel permeation chromatography (1260 infinity GPC/SEC, Agilent technologies). The solute rejection $\mathrm{R}_{\mathrm{T}}(\%)$ was calculated using the equation:

$$
R_{T}(\%)=\left(1-\frac{c_{p}}{c_{f}}\right)
$$

where $c_{p}$ and $c_{f}$ are the solute concentrations in the permeate and feed solution, respectively. From the relationship between $\mathrm{R}_{\mathrm{T}}(\%)$ and solute molecular weight, pore size, pore size distribution, and MWCO can be calculated as described previously [26].

\subsection{Ultrafiltration tests}

The ultrafiltration performance was examined by filtration tests of different proteins, with the same set-up used for pore size tests. These solutions were prepared in phosphate phosphate 
buffered saline solution. Their rejection was calculated by Eq. (3), based on their permeate and feed concentrations, which were analyzed on a UV spectrometer at $280 \mathrm{~nm}$ (Thermo scientific, Nanodrop 2000c).

\section{Results and Discussion}

\subsection{Effect of different coagulants on the phase diagrams}

Different coagulants have been investigated in this study to fabricate porous hollow fibers, which include common coagulants - the non-solvent water and the mixture of solvent and non-solvent (NMP and water) - and newly proposed coagulants - EG and their mixture with water. The nature of coagulants contributes to govern the precipitation rate of the polymer dope, which is an important parameter for fabricating porous membranes. Figure 3 depicts the cloud points of the polymer dopes with different concentrations, when they were well mixed with the coagulants. The red line is very close to the solvent axis, which implies that water is a strong non-solvent for the PEI polymer. This agrees with the huge difference in their solubility parameters $\left(26.3 \mathrm{MPa}^{1 / 2}\right.$ for PEI and 47.8 $\mathrm{MPa}^{1 / 2}$ for water) as presented in Table 3. As a result, even small amount of water can lead to thermodynamic instability and induce solution turbidity. The water concentration is almost constant for all solutions (around $1 \mathrm{wt} \%$ ). 


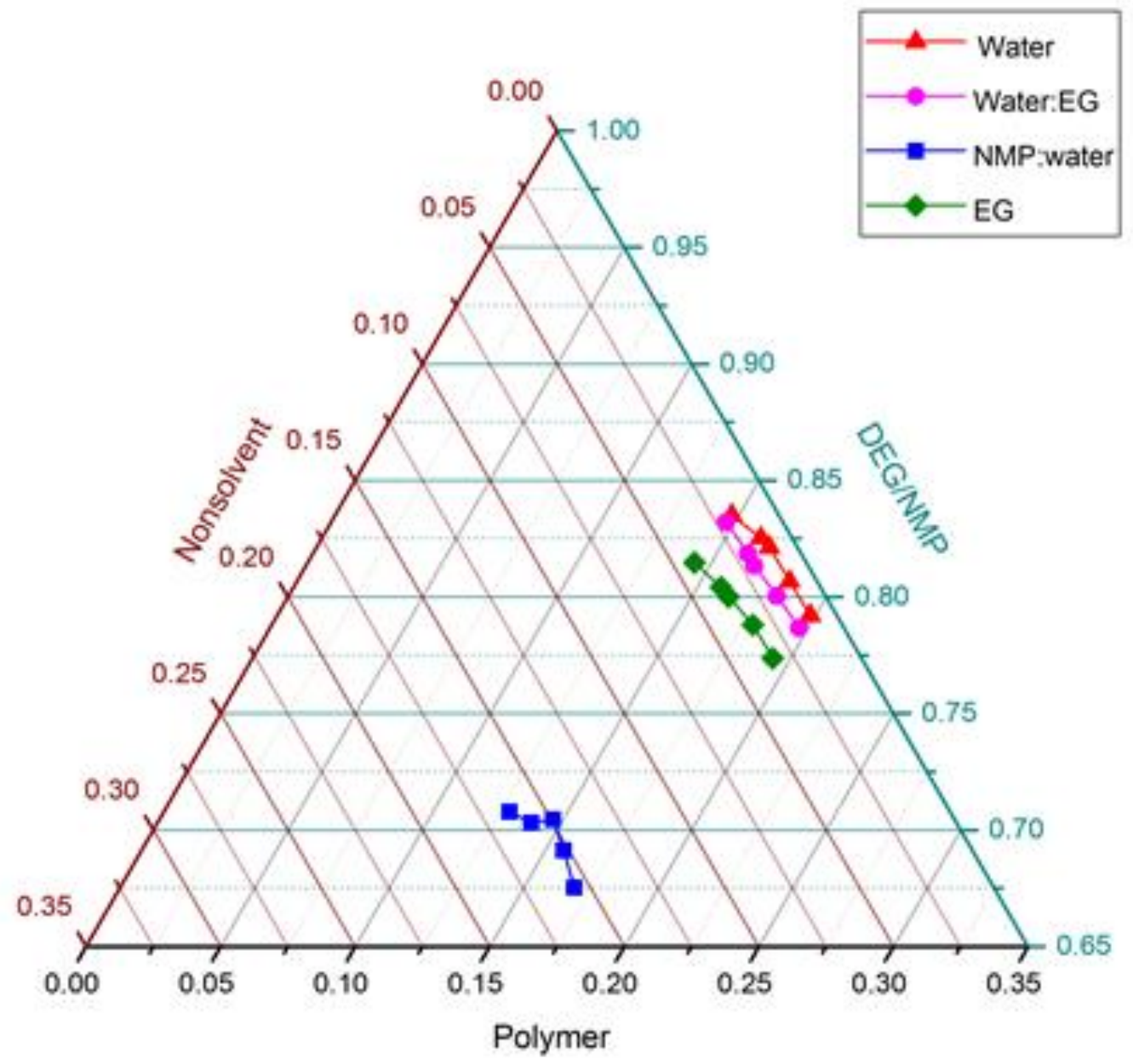

Figure 3. Phase diagram of PEI/solvent/non-solvent systems at $60{ }^{\circ} \mathrm{C}$.

The mixture of NMP:water (9:1) significantly shifts the system far apart from the axis. More coagulant is required to induce phase separation, since NMP alone is a solvent for PEI. This low precipitation rate leads to a delayed demixing of the polymer dope when the mixture is used as the bore fluid for fiber spinning.

Compared to water, EG (solubility parameter of $32.9 \mathrm{MPa}^{1 / 2}$ ) is a weak non-solvent for PEI, and promotes demixing at a slower rate than water. The binodal curve for 1:1 water:EG (pink) is close to the binodal curve for water (red). 
Table 3. Solvents solubility parameters. [27]

\begin{tabular}{|c|c|c|c|c|}
\hline \multirow[t]{2}{*}{ Solvent } & \multicolumn{4}{|c|}{ Solubility parameter $\left(\mathrm{MPa}^{1 / 2}\right)$} \\
\hline & $\begin{array}{l}\text { Dispersive } \\
\text { parameter } \delta_{d}\end{array}$ & $\begin{array}{l}\text { Polar } \\
\text { parameter } \delta_{p}\end{array}$ & $\begin{array}{l}\text { Hydrogen bonding } \\
\text { parameter } \delta_{\mathrm{h}}\end{array}$ & $\begin{array}{l}\text { Total solubility } \\
\text { parameter } \delta_{\mathrm{t}}\end{array}$ \\
\hline NMP & 18.0 & 12.3 & 7.2 & 22.9 \\
\hline NMP:water (9:1) & - & - & - & $25.5^{\mathrm{a}}$ \\
\hline water & 15.6 & 16.0 & 42.3 & 47.8 \\
\hline EG & 17.0 & 11.0 & 26.0 & 32.9 \\
\hline Water:EG $(1: 1)$ & - & - & - & $40.7^{\mathrm{a}}$ \\
\hline PEI & - & - & - & 26.3 \\
\hline
\end{tabular}

${ }^{a}$ The values were calculated accordingly to the mathematical method for solvent mixtures in ref [27].

\subsection{Kinetics of phase inversion with different coagulants}

Precipitation kinetics or phase inversion kinetics is important to understand the membraneforming mechanism. Figure 4 depicts the precipitation kinetics of the PEI solution in different coagulants by light transmittance measurement, similar to that described by Reuvers and Smolders [28]. The precipitation rate is in the order of water > water:EG > EG > NMP:water. Liquid-liquid phase separation can occur by spinodal decomposition (SD) or nucleation and growth (NG) $[29,30]$. SD is preferentially favored when the system is abruptly brought to a twophase condition. This is probably the case of the fast coagulation in water in this investigated system, as well as coagulation in water:EG. On the other hand, when EG or NMP:water are used as coagulants, phase separation is slow. The transition from one to two-phases being slow, allows a long period in a metastable condition, which favors the NG mechanism. 


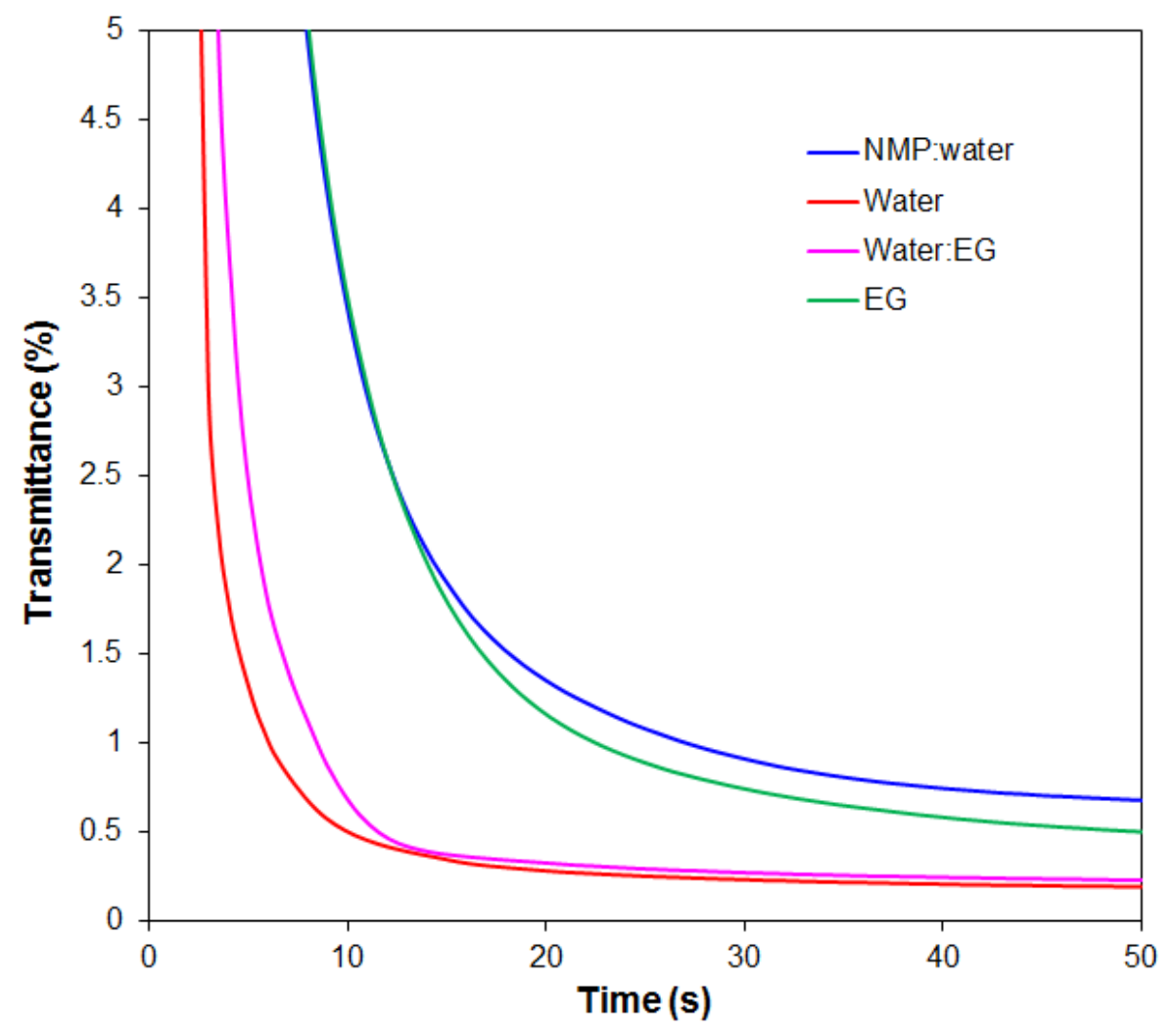

Figure 4. Plots of light transmittance vs time for PEI solution in different coagulants.

The kinetics of phase separation is strongly influenced by the non-solvent viscosity and by the solvent/non-solvent miscibility. EG is 16 -fold more viscous than water and 10-fold more than NMP, as listed in Table 4. In the cloud point tests, stirring facilitates the mixing of EG and PEI/NMP solution. As a result, EG can express its full function as a non-solvent and easily induce thermodynamic instability. On the contrary, in the precipitation kinetics, which partially mimics the phase separation during membrane formation, EG approaches the thin polymer solution film and forms a skin at the solution/non-solvent interface. The skin becomes a barrier to restrict the diffusion of EG, and due to its high viscosity the solvent/non-solvent exchange becomes even slower, as seen in Figure 4. When water:EG is used as non-solvent mixture the 
viscosity is much lower and the phase separation follows a mechanism similar to that observed in pure water as coagulant.

Table 4. Solvents physical properties. [31]

\begin{tabular}{lllll}
\hline Solvent & $\begin{array}{l}\text { Molecular } \\
\text { volume }\left(\AA^{\mathbf{3}}\right)\end{array}$ & $\begin{array}{l}\text { Boiling point } \\
\left({ }^{\mathbf{0}} \mathbf{C}\right)\end{array}$ & $\begin{array}{l}\text { Viscosity } \\
\left(\mathbf{1 0}^{-3} \mathbf{P a . s}\right)\end{array}$ & $\begin{array}{l}\text { Density } \\
\left(\mathbf{g} / \mathbf{c m}^{\mathbf{3}}\right)\end{array}$ \\
\hline NMP & 160 & 202 & 1.65 & 1.028 \\
water & 30 & 100 & 1 & 1 \\
EG & 55.8 & 197 & 16.1 & 1.113 \\
\hline
\end{tabular}

The reason for the low precipitation rate in NMP:water (9:1) is different than in EG. Since a large amount of NMP is present in the coagulant (low water concentration), the osmotic force driving the solvent diffusion to the non-solvent (bore fluid) and the simultaneous diffusion of non-solvent into the dope solution is low. As a result, the solvent/non-solvent exchange is slow. In addition to that, as depicted in its phase diagram, the NMP:water (9:1) mixture is a very weak non-solvent for PEI and hence more non-solvent is required to lead to precipitation.

\subsection{Membrane morphologies}

Figures 5 and 6 display cross-sectional and surface morphologies of PEI hollow fiber membranes spun with different bore fluids. A comparison between the first two rows in these two figures shows the difference in morphology when NMP:water is used as bore fluid instead of water. The fiber spun with NMP:water has a mixed structure of one sponge-like layer and one finger-like layer while the fiber spun with water has two virtually symmetric finger-like layers. In addition, the former has a larger overall diameter with a thinner wall thickness, more porous sublayers (at the inner and outer edges) than the latter. Their inner surfaces indicate that the NMP:water as 
bore fluid produces a highly porous layer with large pores, while water generates a relatively dense layer with no pores detected even at high magnification. Although their outer surfaces have a similar structure, their pores have different sizes with the smaller one observed for the fiber spun with water. When NMP:water is used, a delayed demixing takes place from the lumen side and a rapid demixing occurs from the shell side (because water is used as the external coagulant). Under the rapid demixing condition, the membrane has a very thin outer top layer (as depicted in its outer edge image) and a sublayer with finger-like macrovoids. 
(a)
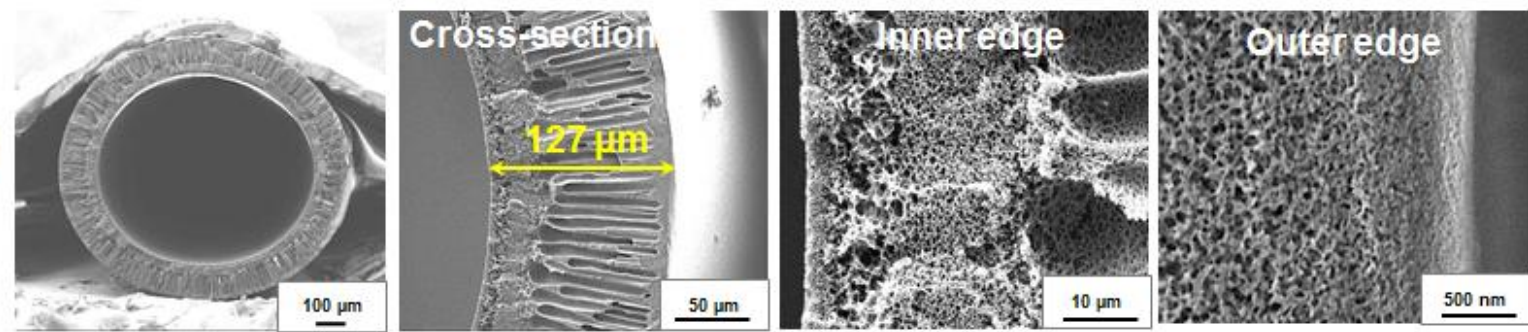

(b)
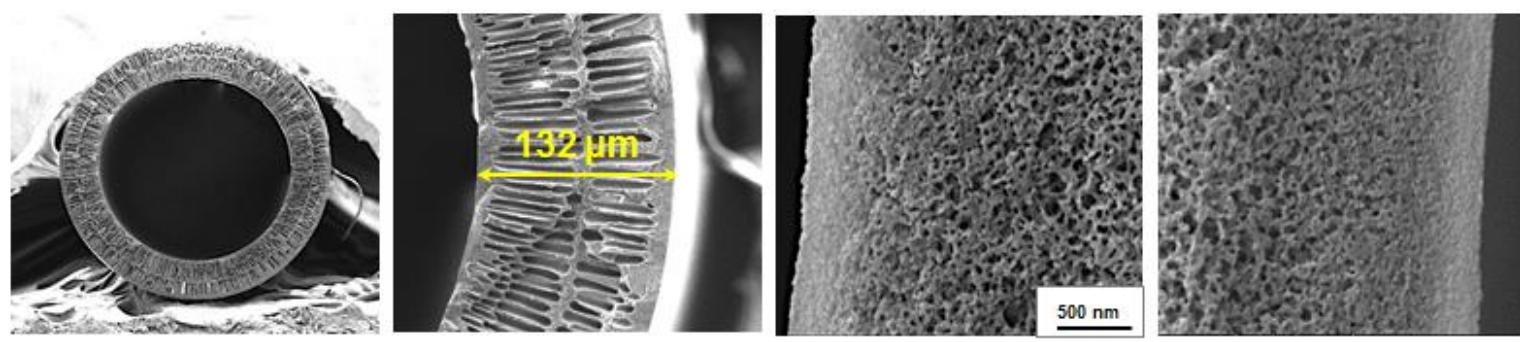

(c)
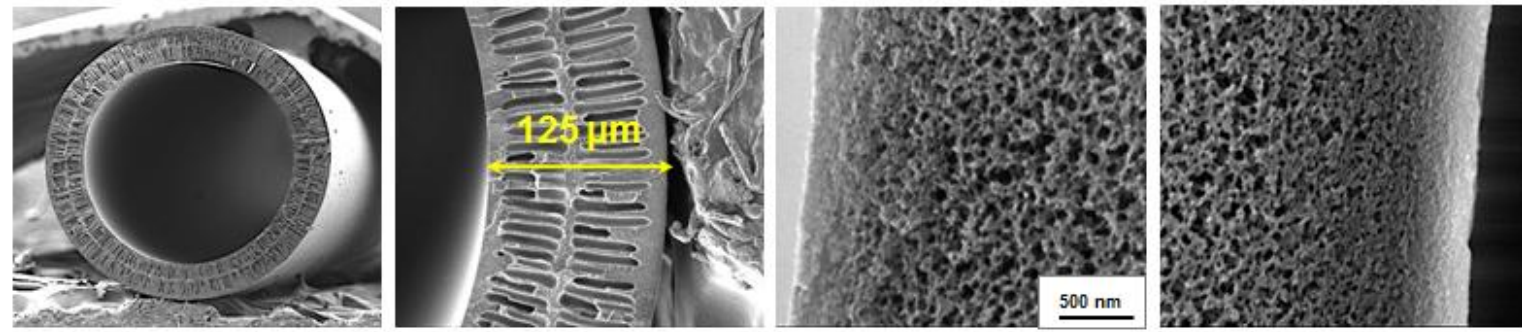

(d)
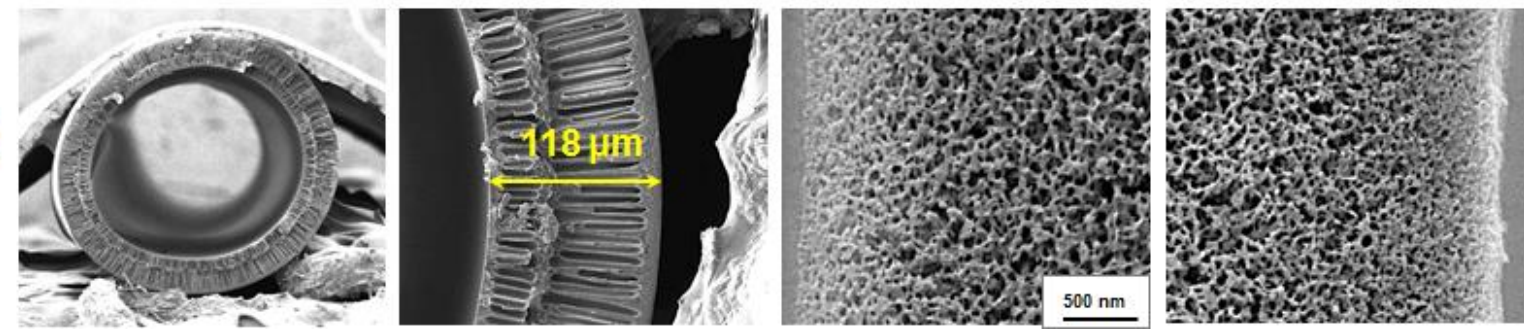

Figure 5. Cross-sectional morphologies of fiber membranes spun with different bore fluids: (a)

NMP:water (9:1); (b) water; (c) water:EG (1:1) and (d) EG. 


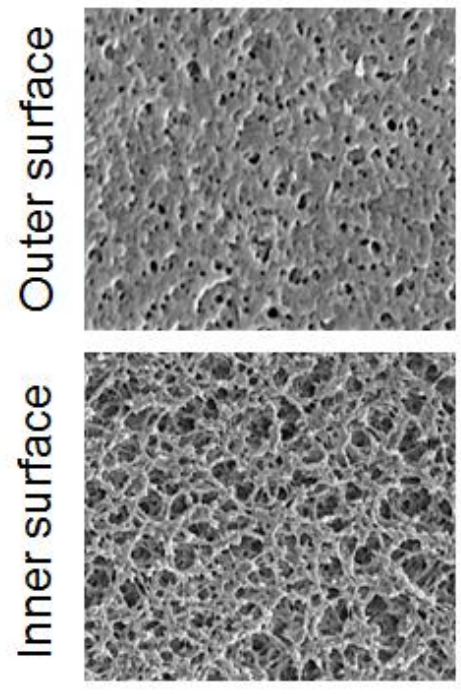

(a)
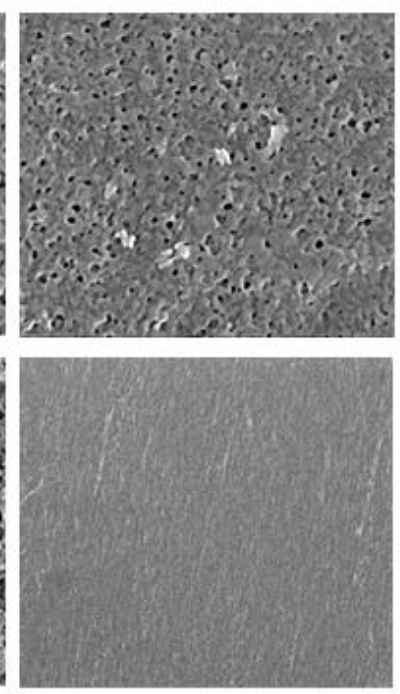

(b)
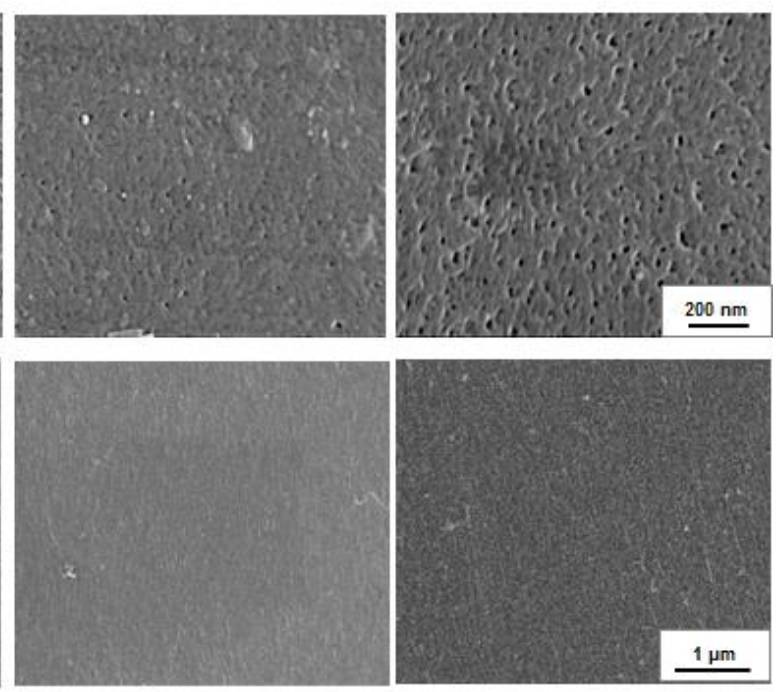

(c)

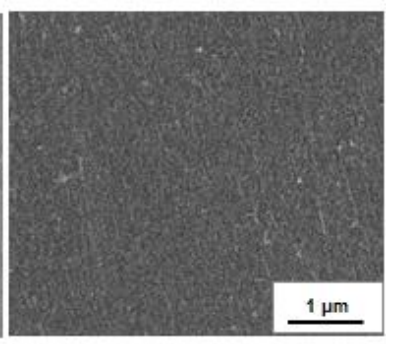

(d)

Figure 6. Surface morphologies of fiber membranes spun with different bore fluids: (a) NMP:water (9:1); (b) water; (c) water: EG (1:1) and (d) EG.

The dimensional difference between fibers spun with NMP:water and water can be explained by their coagulant strength and the difference in diffusion rates of solvent to the coagulation bath (or bore fluid stream) and non-solvent diffusion into the dope. As discussed from their phase diagram and precipitation kinetics, water is a strong coagulant. When the nascent fiber encounters water from lumen and shell sides, its inner and outer surfaces are immediately solidified and hence its shape and dimension are virtually fixed and less affected subsequently by the internal and elongation forces. On the contrary, the weak coagulant NMP:water produces an elastic and flexible cylindrical fiber at the early stage which can be dimensionally changed under forces. Its larger diameter and smaller thickness indicate that the internal force from the lumen may dominate in this case. 
The last three rows of images in Figures 5 and 6 show the morphological transition of the fibers by gradually changing the bore fluid from water to EG. Although all of them have a finger-like bilayered structure, the symmetry is lost when EG is used as bore fluid. Although EG leads to a slow precipitation rate similar to NMP:water as shown in Figure 4, their overall morphologies are different. As explained above the solvent/non-solvent exchanges in the two systems are governed by different parameters. Water diffuses into the dope faster than EG, due to the difference in their viscosity. More NMP is allowed to diffuse out of the dope while EG goes into the dope to promote phase separation and membrane solidification. A thinner fiber wall is then obtained (Figure 5d compared to Figures $5 \mathrm{~b}$ and c) when high content of EG is used instead of water. In addition, compared to water, EG produces a more elastic nascent cylindrical fiber, the wall thickness of which is more easily narrowed by the combined compression of the internal force from the lumen and the elongational stress from the outer. The delayed demixing observed with EG suppresses the macrovoid formation at least in part. The finger-like macrovoids become smaller and the sublayers close to the top layers turn into more porous sponge-like structures.

The comparison between the outer surfaces of the three hollow fibers spun with water, water:EG and EG shows that the 1:1 water:EG mixture produces the fiber with the smallest pores on the outer surface. This observation is due to the fact that the structure of the top layer (porous or dense) also depends on the time that phase separation is allowed to proceed and how much solvent goes out of the dope before solidification. EG promotes slow phase separation and hence the membrane solidification takes place with a higher polymer concentration (solvent outflow larger than non-solvent inflow) in a system spun with EG. Another aspect is how impermeable the incipient skin is at the interface between dope and coagulant. When pure EG is used as bore fluid, the skin may be completely formed only at later stages of phase inversion. When water:EG 
is used, the skin is formed faster, freezing a structure with smaller pores at an earlier stage of phase separation.

\subsection{Membrane physicochemical properties}

Table 5 lists the physicochemical properties of PEI hollow fiber membranes. Porosity strongly affects the membrane permeation and increases in the following order: water > NMP:water > water:EG > EG. Although the fibers spun with NMP:water as coagulant has a highly porous inner and outer surfaces, and an open cross-sectional structure at the inner edge, as shown in SEM images (Figures 5 and 6), the total porosity is lower than that of fibers spun with water, because the number of finger-like macrovoids is smaller. Similarly, although the presence of EG in bore fluid increases the porosity of the sublayers close to the surfaces, it disfavors the formation of finger-like macrovoids and hence decreases the overall porosity. 
Table 5. Characteristics of the PEI hollow fiber membranes spun with different bore fluids.

\begin{tabular}{lllll}
\hline $\begin{array}{l}\text { Membrane } \\
\text { sample }\end{array}$ & $\begin{array}{l}\text { Contact } \\
\text { angle }^{\mathbf{(}} \text { ) }\end{array}$ & Porosity (\%) & $\begin{array}{l}\text { Mean pore } \\
\text { size (nm) }\end{array}$ & $\begin{array}{l}\text { MWCO } \\
\left(\mathbf{k g ~ m o l}^{-1}\right)\end{array}$ \\
\hline NMP:water (9:1) & 89 & $74.8 \pm 0.5$ & $10.2 \pm 1.8$ & 97 \\
Water & 89 & $77.7 \pm 0.4$ & $9.1 \pm 1.7$ & 74 \\
Water:EG (1:1) & 89 & $74.4 \pm 0.4$ & $8.2 \pm 1.7$ & 59 \\
EG & 89 & $72.0 \pm 0.5$ & $8.6 \pm 1.7$ & 67 \\
\hline
\end{tabular}

The pore structural characteristics of fiber outer surfaces were evaluated, by solute filtration tests. Figure 7 depicts the solute rejection versus solute molecular weight and their pore size distribution. From these data, the mean pore size, and molecular weight cut-off (MWCO) were calculated and listed in Table 5. Consistent with the SEM images, the mean pore size and MWCO decreases in the following order: NMP:water > water > EG > water:EG.

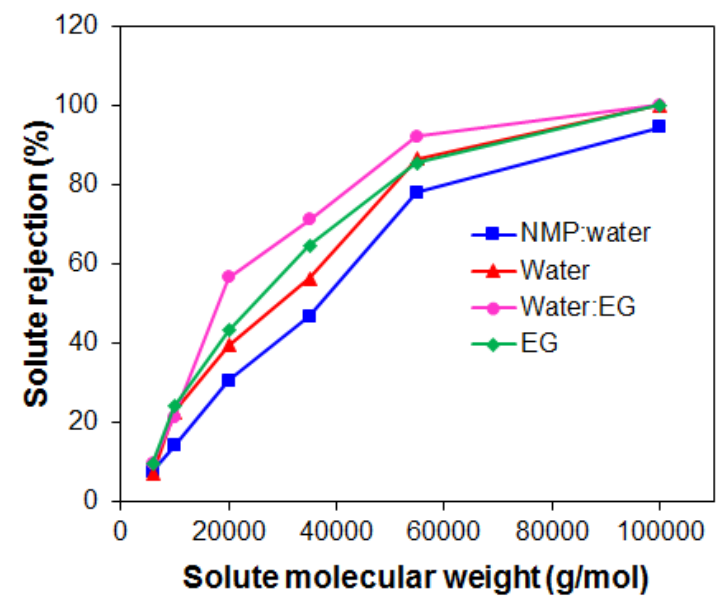

(a)

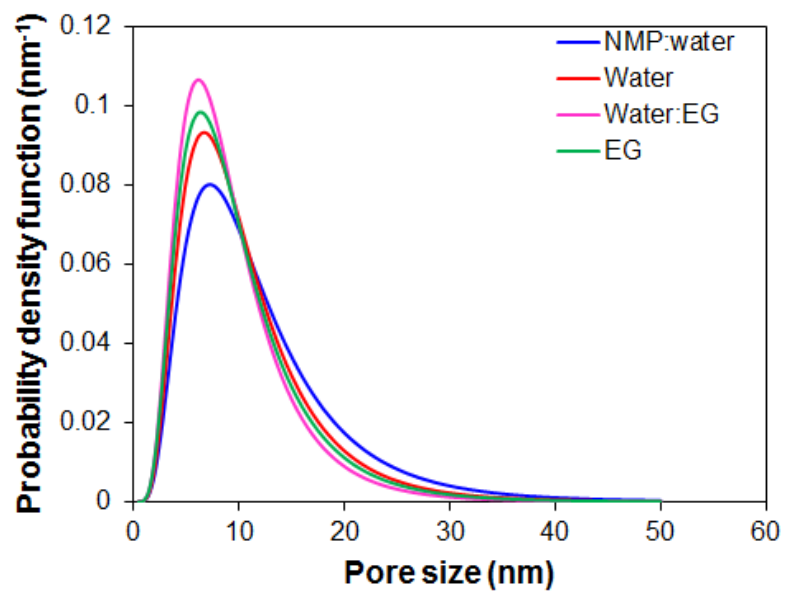

(b)

Figure 7. Solute rejection and pore size distribution of PEI hollow fiber membranes spun with different bore fluids. 
The hydrophilicity of the membranes was investigated by measuring the water contact angles. There is no significant difference in contact angle for all fibers spun with different bore fluids. The contact angle of a membrane depends on the material chemistry and surface roughness. Although there are pore size differences among the fibers, the difference is in the nanometer range and did not have a remarkable effect. It indicates also that ethylene glycol is not retained in the membrane matrix.

\subsection{Ultrafiltration performance}

Table 6 provides the pure water permeance and protein rejection for all fibers. Three kinds of protein were tested: myoglobin, BSA and $\gamma$-globulin. The pure water permeance increases in the following order: EG > NMP:water > water:EG > water. Interestingly, although the fiber spun with EG has the lowest total porosity, it achieves the highest pure water permeance. This is the combined result of its finger-like bilayered structure and porous sublayers close to the surfaces. The fiber spun with the common bore fluid of NMP:water has the lowest protein rejection with a high MWCO $\left(97 \mathrm{~kg} \mathrm{~mol}^{-1}\right)$. Its rejections for BSA and $\gamma$-globulin are still higher than $90 \%$. Other fibers can reject $100 \% \gamma$-globulin $\left(155-160 \mathrm{~kg} \mathrm{~mol}^{-1}\right)$ and $>98 \%$ BSA $\left(\sim 66 \mathrm{~kg} \mathrm{~mol}^{-1}\right)$. Rejection is a function of pore size and charge. PEI membranes were reported to be negatively charged at $\mathrm{pH} 7$ [32]. At this $\mathrm{pH}$ value, BSA with the isoelectric point of $\sim 4.8$ also have the same sign of charge. Therefore, the electrostatic repulsion plays an important role in supportively reject BSA from the PEI membrane surface. Since all membranes have remarkably high rejection of $\gamma$-globulin and BSA, a smaller protein molecule with an isoelectric point of close to the neutral $\mathrm{pH}$, i.e. myoglobin ( $17 \mathrm{kDa}$, pI 7.3), was used to evaluate the sieving effect of the fibers. As expected, the myoglobin rejection follows the similar trend with the surface pore size. 
Noticeably, the fiber spun with water:EG has a relatively high rejection of $\sim 80 \%$ for myoglobin, which implies that by adding EG to the bore fluid membrane structure, porosity and surface pore size could be tailored for better separation performance. Other related liquids (high viscosity, high miscibility with water, and weak non-solvent strength) such as diethylene glycol, glycerol and polyethylene glycol may have similar effects. Ethylene glycol was chosen because of its relatively small molecular weight. Effects of higher molecular weights may include further restricted diffusion, lower solvent/non-solvent exchange and hence need further investigation.

Table 6. Pure water permeability and protein rejection of PEI hollow fiber membranes spun with different bore fluids.

\begin{tabular}{lllll}
\hline Bore fluid & $\begin{array}{l}\text { Pure water } \\
\text { permeance } \\
\left(\mathbf{L m}^{-2} \mathbf{h}^{-1} \mathbf{b a r}^{-1}\right)\end{array}$ & $\begin{array}{l}\text { Myoglobin } \\
\text { rejection (\%) }\end{array}$ & $\begin{array}{l}\text { BSA } \\
\text { rejection (\%) }\end{array}$ & $\begin{array}{l}\gamma \text {-Globulin } \\
\text { rejection (\%) }\end{array}$ \\
\hline NMP:water (9:1) & 338 & 33 & 91 & 96 \\
Water & 217 & 38 & 98 & 100 \\
Water:EG (1:1) & 254 & 80 & 98 & 100 \\
EG & 368 & 63 & 98 & 100 \\
\hline
\end{tabular}

Table 7 shows the filtration performance of PEI ultrafiltration membranes reported in the literature in comparison with those in this study. The data imply that the technique of membrane preparation can lead to significant differences in their performance. Our proposed approach, introduction of a viscous liquid (i.e. ethylene glycol) as a bore fluid component, produces fiber membranes with a higher water permeance and much better protein rejection with a narrower surface pore size (smaller molecular weight cut-off).

Table 7. Filtration performance of PEI membranes. 


\begin{tabular}{|c|c|c|c|c|c|}
\hline Membrane & $\begin{array}{l}\text { Membrane } \\
\text { configuration }\end{array}$ & $\begin{array}{l}\text { Pure water } \\
\text { permeance } \\
\left(\mathbf{L ~ m}^{-2} \mathbf{h}^{-1} \text { bar }^{-1}\right)\end{array}$ & $\begin{array}{l}\text { Solute } \\
\text { rejection } \\
(\%)\end{array}$ & $\begin{array}{c}\text { Solute molecular } \\
\text { weight } \\
\left(\mathrm{kg} \mathrm{mol}^{-1}\right)\end{array}$ & Ref. \\
\hline $\begin{array}{l}\text { PEI/PEG/NMP } \\
(18 / 6 / 76)\end{array}$ & Flat-sheet & $\sim 400$ & $\sim 85$ & $\gamma$-globin (157) & [33] \\
\hline $\begin{array}{l}\text { PEI/PVP/NMP } \\
(17.5 / 8 / 74.5)\end{array}$ & Flat-sheet & $\sim 175$ & 85.2 & $\mathrm{BSA}(\sim 66)$ & {$[34]$} \\
\hline $\begin{array}{l}\text { PEI/NMP } \\
(16 / 84)\end{array}$ & Flat-sheet & $\sim 160$ & $\sim 99$ & $\mathrm{BSA}(\sim 66)$ & {$[35]$} \\
\hline $\begin{array}{l}\text { PEI/DMAc } \\
(25 / 75)\end{array}$ & Hollow fiber & 30 & 81 & Dextran (40) & [36] \\
\hline $\begin{array}{l}\mathrm{PEI} / \mathrm{HAc} / \mathrm{DMA} \\
\mathrm{c}(25.0 / 5.4 / 69.6)\end{array}$ & Hollow fiber & 34 & 83 & Dextran (40) & {$[37]$} \\
\hline \multirow{2}{*}{$\begin{array}{l}\mathrm{PEI} / \mathrm{DEG} / \mathrm{NMP} \\
(17 / 13 / 70)\end{array}$} & \multirow[t]{2}{*}{ Hollow fiber } & \multirow[t]{2}{*}{368} & 98.4 & $\mathrm{BSA}(\sim 66)$ & \multirow{2}{*}{$\begin{array}{l}\text { This } \\
\text { study }\end{array}$} \\
\hline & & & 100 & $\begin{array}{l}\gamma \text {-globulin } \\
(155-160)\end{array}$ & \\
\hline
\end{tabular}

DMAc: dimethylacetamide; HAc: acetic acid

\section{Conclusions}

In this study, different bore fluids including conventional and newly proposed coagulants were used to tailor membrane structures and separation properties for ultrafiltration application. The thermodynamics of the polymer dope solution, kinetics of phase separation, fiber membrane morphologies, physicochemical properties and separation performance were investigated indepth. The following conclusions can be drawn based on this work:

(1) Two strategies for slow precipitation during fiber spinning were demonstrated: one is based on the solvent/non-solvent interaction or osmotic driving force for mixing, while another is based on non-solvent high viscosity. They lead to different morphologies of the resultant membranes. 
(2) The presence of ethylene glycol with its weak non-solvent property and high viscosity in bore fluid can lead to high porosity and improve pure water permeance.

(3) Controlling the ethylene glycol amount in the bore fluid can tune the membrane towards smaller surface pore size for high separation efficiency of a smaller protein.

\section{Acknowledgements}

The work was supported by King Abdullah University of Science and Technology (KAUST).

\section{References}

[1] C.F. Lin, A.Y.C. Lin, P.S. Chandana, C.Y. Tsai, Effects of mass retention of dissolved organic matter and membrane pore size on membrane fouling and flux decline, Water Research, 43 (2009) 389-394.

[2] S. Zhang, P. Sukitpaneenit, T.S. Chung, Design of robust hollow fiber membranes with high power density for osmotic energy production, Chemical Engineering Journal, 241 (2014) 457465.

[3] M. Yeow, Y. Liu, K. Li, Morphological study of poly (vinylidene fluoride) asymmetric membranes: effects of the solvent, additive, and dope temperature, Journal of Applied Polymer Science, 92 (2004) 1782-1789.

[4] A. Bottino, G. Capannelli, S. Munari, A. Turturro, High performance ultrafiltration membranes cast from LiCl doped solutions, Desalination, 68 (1988) 167-177.

[5] E. Yuliwati, A.F. Ismail, Effect of additives concentration on the surface properties and performance of PVDF ultrafiltration membranes for refinery produced wastewater treatment, Desalination, 273 (2011) 226-234. 
[6] E. Fontananova, J.C. Jansen, A. Cristiano, E. Curcio, E. Drioli, Effect of additives in the casting solution on the formation of PVDF membranes, Desalination, 192 (2006) 190-197.

[7] S.R. Panda, S. De, Preparation, characterization and performance of $\mathrm{ZnCl}_{2}$ incorporated polysulfone (PSF)/polyethylene glycol (PEG) blend low pressure nanofiltration membranes, Desalination, 347 (2014) 52-65.

[8] E. Fontananova, J.C. Jansen, A. Cristiano, E. Curcio, E. Drioli, Effect of additives in the casting solution on the formation of PVDF membranes, Desalination, 192 (2006) 190-197.

[9] J.Y. Lai, F.C. Lin, C.C. Wang, D.M. Wang, Effect of nonsolvent additives on the porosity and morphology of asymmetric TPX membranes, Journal of Membrane Science, 118 (1996) 4961.

[10] I.C. Kim, K.H. Lee, Effect of various additives on pore size of polysulfone membrane by phase-inversion process, Journal of Applied Polymer Science, 89 (2003) 2562-2566.

[11] M. Khayet, C. Feng, K. Khulbe, T. Matsuura, Study on the effect of a non-solvent additive on the morphology and performance of ultrafiltration hollow-fiber membranes, Desalination, 148 (2002) 321-327.

[12] S. Deshmukh, K. Li, Effect of ethanol composition in water coagulation bath on morphology of PVDF hollow fibre membranes, Journal of Membrane Science, 150 (1998) 7585.

[13] R. Boom, I. Wienk, T. Van den Boomgaard, C. Smolders, Microstructures in phase inversion membranes. Part 2. The role of a polymeric additive, Journal of Membrane Science, 73 (1992) 277-292. 
[14] M.J. Han, S.T. Nam, Thermodynamic and rheological variation in polysulfone solution by PVP and its effect in the preparation of phase inversion membrane, Journal of Membrane Science, 202 (2002) 55-61.

[15] B. Jung, J.K. Yoon, B. Kim, H.W. Rhee, Effect of molecular weight of polymeric additives on formation, permeation properties and hypochlorite treatment of asymmetric polyacrylonitrile membranes, Journal of Membrane Science, 243 (2004) 45-57.

[16] A. Idris, N.M. Zain, M. Noordin, Synthesis, characterization and performance of asymmetric polyethersulfone (PES) ultrafiltration membranes with polyethylene glycol of different molecular weights as additives, Desalination, 207 (2007) 324-339.

[17] Y. Ma, F. Shi, J. Ma, M. Wu, J. Zhang, C. Gao, Effect of PEG additive on the morphology and performance of polysulfone ultrafiltration membranes, Desalination, 272 (2011) 51-58.

[18] G. Arthanareeswaran, D. Mohan, M. Raajenthiren, Preparation, characterization and performance studies of ultrafiltration membranes with polymeric additive, Journal of Membrane Science, 350 (2010) 130-138.

[19] J.H. Kim, K.H. Lee, Effect of PEG additive on membrane formation by phase inversion, Journal of Membrane Science, 138 (1998) 153-163.

[20] W.Z. Lang, J.P. Shen, Y.X. Zhang, Y.H. Yu, Y.J. Guo, C.X. Liu, Preparation and characterizations of charged poly (vinyl butyral) hollow fiber ultrafiltration membranes with perfluorosulfonic acid as additive, Journal of Membrane Science, 430 (2013) 1-10.

[21] L. Shi, R. Wang, Y. Cao, D.T. Liang, J.H. Tay, Effect of additives on the fabrication of poly (vinylidene fluoride-co-hexafluropropylene)(PVDF-HFP) asymmetric microporous hollow fiber membranes, Journal of Membrane Science, 315 (2008) 195-204. 
[22] J.F. Li, Z.L. Xu, H. Yang, Microporous polyethersulfone membranes prepared under the combined precipitation conditions with non-solvent additives, Polymers for Advanced Technologies, 19 (2008) 251-257.

[23] N.L. Le, N. Bettahalli, S.P. Nunes, T.S. Chung, Outer-selective thin film composite (TFC) hollow fiber membranes for osmotic power generation, Journal of Membrane Science, 505 (2016) 157-166.

[24] N.L. Le, T.S. Chung, High-performance sulfonated polyimide/polyimide/polyhedral oligosilsesquioxane hybrid membranes for ethanol dehydration applications, Journal of Membrane Science, 454 (2014) 62-73.

[25] P. Sukitpaneenit, T.S. Chung, Molecular elucidation of morphology and mechanical properties of PVDF hollow fiber membranes from aspects of phase inversion, crystallization and rheology, Journal of Membrane Science, 340 (2009) 192-205.

[26] D. Kim, N.L. Le, S.P. Nunes, The effects of a co-solvent on fabrication of cellulose acetate membranes from solutions in 1-ethyl-3-methylimidazolium acetate, Journal of Membrane Science, 520 (2016) 540-549.

[27] J. Burke, Solubility parameters: theory and application, (1984).

[28] A. Reuvers, C. Smolders, Formation of membranes by means of immersion precipitation:

Part II. the mechanism of formation of membranes prepared from the system cellulose acetateacetone-water, Journal of Membrane Science, 34 (1987) 67-86.

[29] K.V. Peinemann, J. Maggioni, S. Nunes, Poly (ether imide) membranes obtained from solution in cosolvent mixtures, Polymer, 39 (1998) 3411-3416.

[30] S.P. Nunes, T. Inoue, Evidence for spinodal decomposition and nucleation and growth mechanisms during membrane formation, Journal of Membrane Science, 111 (1996) 93-103. 
[31] I. Smallwood, Handbook of organic solvent properties, Butterworth-Heinemann, 2012.

[32] N.L. Le, M. Quilitzsch, H. Cheng, P.Y. Hong, M. Ulbricht, S.P. Nunes, T.S. Chung, Hollow fiber membrane lumen modified by polyzwitterionic grafting, Journal of Membrane Science, 522 (2017) $1-11$.

[33] J. Chen, J. Li, X. Zhan, X. Han, C. Chen, Effect of PEG additives on properties and morphologies of polyetherimide membranes prepared by phase inversion, Frontiers of Chemical Engineering in China, 4 (2010) 300-306.

[34] P. Kanagaraj, A. Nagendran, D. Rana, T. Matsuura, S. Neelakandan, K. Malarvizhi, Effects of polyvinylpyrrolidone on the permeation and fouling-resistance properties of polyetherimide ultrafiltration membranes, Industrial \& Engineering Chemistry Research, 54 (2015) 4832-4838.

[35] W. Chinpa, D. Quémener, E. Bèche, R. Jiraratananon, A. Deratani, Preparation of poly (etherimide) based ultrafiltration membrane with low fouling property by surface modification with poly (ethylene glycol), Journal of Membrane Science, 365 (2010) 89-97.

[36] L.Q. Shen, Z.K. Xu, Z.M. Liu, Y.Y. Xu, Ultrafiltration hollow fiber membranes of sulfonated polyetherimide/polyetherimide blends: preparation, morphologies and anti-fouling properties, Journal of Membrane Science, 218 (2003) 279-293.

[37] Z.K. Xu, L.Q. Shen, Q. Yang, F. Liu, S.Y. Wang, Y.Y. Xu, Ultrafiltration hollow fiber membranes from poly (ether imide): preparation, morphologies and properties, Journal of Membrane Science, 223 (2003) 105-118.

\section{List of abbreviations and nomenclatures}

\section{Abbreviations}

HAc $\quad$ : acetic acid 


$\begin{array}{ll}\text { BSA } & : \text { bovine serum albumin } \\ \text { DEG } & : \text { diethylene glycol } \\ \text { DMAc } & : \text { (2-dimethyl amino) ethyl methacrylate-co-butyl methacrylate) } \\ \text { EG } & : \text { ethylene glycol } \\ \text { FESEM } & : \text { field emission scanning electron microscope } \\ \text { MWCO } & : \text { molecular weight cut-off } \\ \text { NG } & : \text { nucleation and growth } \\ \text { NMP } & : \text { N-methyl-pyrrolidone } \\ \text { PEG } & : \text { poly(ethyleneglycol) } \\ \text { PEI } & : \text { polyetherimide } \\ \text { PEO } & : \text { poly(ethylene oxide) } \\ \text { PVD } & : \text { polyvinylidene fluoride } \\ \text { PVP } & : \text { isoelectric point } \\ \text { PD } & \end{array}$

\section{Nomenclatures}

$\begin{array}{ll}\mathrm{A}_{\mathrm{m}} & : \text { effective membrane area }\left(\mathrm{m}^{2}\right) \\ \text { ID } & : \text { inner diameter }(\mu \mathrm{m}) \\ \text { OD } & : \text { outer diameter }(\mu \mathrm{m}) \\ \mathrm{Q} & : \text { water permeation volumetric flow rate }(\mathrm{L} / \mathrm{h}) \\ \mathrm{R}_{\mathrm{T}} & : \text { solute rejection }(\%)\end{array}$




$\begin{array}{ll}\mathrm{c}_{\mathrm{p}} & : \text { solute concentration in the permeate }(\mathrm{ppm}) \\ \mathrm{c}_{\mathrm{f}} & : \text { solute concentration in the feed }(\mathrm{ppm}) \\ \mathrm{l} & : \text { length }(\mathrm{cm}) \\ \mathrm{m} & : \text { weight }(\mathrm{mg}) \\ \mathrm{t} & : \text { time }(\mathrm{s}) \\ \Delta \mathrm{P} & : \text { transmembrane pressure }(\mathrm{bar}) \\ \Delta \mathrm{v} & : \text { volume }(\mathrm{L}) \\ \varepsilon & : \text { porosity }(\%) \\ \rho & : \text { density }\left(\mathrm{g} / \mathrm{cm}^{3}\right)\end{array}$

